\title{
Management of critically ill patients receiving noninvasive and invasive mechanical ventilation in the emergency department
}

\author{
This article was published in the following Dove Press journal: \\ Open Access Emergency Medicine \\ 21 March 2012 \\ Number of times this article has been viewed
}

\author{
Louise Rose \\ Lawrence S Bloomberg Faculty \\ of Nursing, University of Toronto, \\ Toronto, Ontario, Canada
}

\begin{abstract}
Patients requiring noninvasive and invasive ventilation frequently present to emergency departments, and may remain for prolonged periods due to constrained critical care services. Emergency clinicians often do not receive the same education on management of mechanical ventilation or have similar exposure to these patients as do their critical care colleagues. The aim of this review was to synthesize the evidence on management of patients requiring noninvasive and invasive ventilation in the emergency department including indications, clinical applications, monitoring priorities, and potential complications. Noninvasive ventilation is recommended for patients with acute exacerbation of chronic obstructive pulmonary disease or cardiogenic pulmonary edema. Less evidence supports its use in asthma and other causes of acute respiratory failure. Use of noninvasive ventilation in the prehospital setting is relatively new, and some evidence suggests benefit. Monitoring priorities for noninvasive ventilation include response to treatment, respiratory and hemodynamic stability, noninvasive ventilation tolerance, detection of noninvasive ventilation failure, and identification of air leaks around the interface. Application of injurious ventilation increases patient morbidity and mortality. Lung-protective ventilation with low tidal volumes based on determination of predicted body weight and control of plateau pressure has been shown to reduce mortality in patients with acute respiratory distress syndrome, and some evidence exists to suggest this strategy should be used in patients without lung injury. Monitoring of the invasively ventilated patient should focus on assessing response to mechanical ventilation and other interventions, and avoiding complications, such as ventilator-associated pneumonia. Several key aspects of management of noninvasive and invasively ventilated patients are discussed, with a particular emphasis on initiation and ongoing monitoring priorities focused on maintaining patient safety and improving patient outcomes.
\end{abstract}

Keywords: mechanical ventilation, emergency department, noninvasive ventilation, critical illness, acute respiratory failure

\section{Introduction}

Management of critically ill patients requiring mechanical ventilation is highly resourceintensive and time-sensitive. ${ }^{1}$ These patients require a high level of care and are at high risk of adverse events. Insufficient monitoring and/or substandard management of these patients may pose a substantial threat to patient safety, leading to complications and adverse outcomes. Management of critical illness is now recognized as a continuum that begins with prehospital care, continues with emergency department intervention and culminates in intensive care unit admission and management. ${ }^{1}$ However, in the emergency department, clinician exposure to this high-risk patient population
Lawrence S Bloomberg Faculty of Nursing, University of Toronto, I55 College St, Room 276, Toronto, Ontario, Canada, M5T IP8

Tel + I 4169783492

$\mathrm{Fax}+\mathrm{I} 4169788222$

Email louise.rose@utoronto.ca 
may be variable. Moreover, emergency departments often lack the resources and personnel trained for longitudinal management of the critically ill. ${ }^{2-4}$ Training of emergency physicians and nurses in the ongoing management of invasively and noninvasively ventilated patients is generally limited, ${ }^{5}$ particularly in North America, where mechanical ventilation is usually initiated and managed by respiratory therapists. However, these clinicians with specialized training in the management of ventilation typically leave the emergency department once the patient is stabilized, and only return to reassess patients and to facilitate transfers at the request of emergency department staff.

In the US, the proportion of critically ill patients presenting to emergency departments is rising and their length of stay in the emergency department is increasing. ${ }^{6-8}$ Delayed admission to an intensive care unit from the emergency department may occur due to hospital crowding and a lack of available intensive care unit beds. ${ }^{1,2}$ Urban US emergency departments report providing more than 150 days of critical care annually., ${ }^{2,9}$ A single-center retrospective Canadian study ${ }^{10}$ reported that critically ill patients accounted for $0.26 \%$ of all emergency department admissions, with a median length of stay of 4.9 hours. This may be an underestimation of the prevalence of critically ill patients, because those admitted from the emergency department to the intensive care unit for surgical, cardiac, or trauma diagnoses were excluded. A more recent prospective, multicenter Canadian study ${ }^{11}$ identified that ventilated patients (invasive and noninvasive) represented $0.5 \%$ of all emergency department presentations, but were not infrequent (0.8 patients per study day per emergency department). Patients remained in the emergency department for a median (interquartile) duration of 6.4 (2.8-14.6) hours, with 11.5\% having a length of stay in the emergency department longer than 24 hours, demonstrating the need for emergency clinicians to provide longitudinal intensive care unit level care in the emergency department. The aim of this narrative review is to summarize the indications, clinical applications, monitoring priorities, and potential complications for critically ill patients receiving noninvasive and invasive ventilation in the emergency department.

\section{Noninvasive ventilation Physiological benefits}

Noninvasive ventilation is effective for patients with acute respiratory failure due to reduced inspiratory muscle work and thus fatigue through the addition of inspiratory positive pressure. ${ }^{12}$ Positive pressure increases transpulmonary pressure, inflates the lungs, augments alveolar ventilation, and unloads the inspiratory muscles. ${ }^{13}$ The increased tidal volume as a result of augmented alveolar ventilation increases carbon dioxide $\left(\mathrm{CO}_{2}\right)$ elimination and reverses acidemia. The use of positive end-expiratory pressure (PEEP) increases functional residual capacity, recruits collapsed alveoli, and improves oxygenation. ${ }^{14}$ Positive pressure also increases intrathoracic pressure, which may improve cardiac performance by reducing myocardial work and oxygen consumption through reduced venous return and ventricular preload, as well as left ventricular afterload. ${ }^{14-16}$

\section{Indications}

Over recent years, use of noninvasive ventilation in the emergency department has increased, particularly for the management of acute cardiogenic pulmonary edema and exacerbation of chronic obstructive pulmonary disease (COPD). ${ }^{17}$ Noninvasive ventilation minimizes some of the complications associated with invasive ventilation, such as ventilator-associated pneumonia, ventilator-associated lung injury, and pneumothorax. Indications for noninvasive ventilation include dyspnea, moderate to severe tachypnea, signs of increased work of breathing, such as accessory muscle use and abdominal paradox, acute (or acute on chronic) ventilatory failure, and hypoxemia. Potential candidates for noninvasive ventilation should have an intact level of consciousness with the ability to maintain a patent airway and spontaneous breathing efforts.

\section{Acute exacerbation of COPD}

A recent meta-analysis of use of noninvasive ventilation for acute exacerbation of COPD identified 16 randomized controlled trials evaluating noninvasive ventilation plus standard therapy compared with standard therapy alone, and reported a lower incidence of endotracheal intubation and hospital mortality for patients receiving noninvasive ventilation. ${ }^{18} \mathrm{COPD}$ patients most likely to respond favorably to noninvasive ventilation are those with an intact level of consciousness, moderate acidemia, respiratory rate prior to initiation of $<30$ breaths/minute, and those who demonstrate improvement within 2 hours of commencement of noninvasive ventilation. ${ }^{12,19}$ Noninvasive ventilation can be delivered as either noninvasive positive pressure ventilation (NIPPV) or continuous positive airway pressure (CPAP; see "ventilator modes and settings"). Because the majority of trials have been conducted using NIPPV, guidelines recently developed by the Canadian Critical Care Trials Group do not make a recommendation regarding use of continuous positive airway pressure for COPD exacerbation. ${ }^{18}$ 


\section{Acute exacerbation of cardiogenic pulmonary edema}

Early use of noninvasive ventilation, either as NIPPV or CPAP, in combination with standard therapy for acute cardiogenic pulmonary edema, has been shown to reduce endotracheal intubation and mortality when compared with standard therapy alone in a number of meta-analyses published prior to $2009 .{ }^{20-25}$ More recently, the largest trial of noninvasive ventilation in acute cardiogenic pulmonary edema (the $3 \mathrm{CPO}$ trial) conducted to date did not demonstrate reduced rates of endotracheal intubation or short-term mortality. ${ }^{26} \mathrm{~A}$ subsequent meta-analysis of 31 studies that included the $3 \mathrm{CPO}$ trial, 17 of which were conducted in the emergency department setting, reported reduced mortality and need for intubation with CPAP and reduced endotracheal intubation but no effect on mortality with NIPPV. ${ }^{27}$ Based on an early study comparing NIPPV with CPAP that reported a higher incidence of myocardial infarction, ${ }^{28}$ practice guidelines for acute cardiogenic pulmonary edema have been hesitant to recommend NIPPV in this patient population. ${ }^{29}$ However, no difference in the incidence of myocardial infarction, endotracheal intubation, or inhospital mortality rates was found in a meta-analysis of 16 studies comparing NIPPV with CPAP. ${ }^{27}$ Therefore, early institution of noninvasive ventilation in combination with standard therapy should be considered routine treatment for acute cardiogenic pulmonary edema and respiratory failure in the absence of acute coronary syndrome that requires urgent revascularization or shock..$^{18}$

\section{Exacerbation of asthma}

Currently, evidence on the role of noninvasive ventilation for acute exacerbation of asthma is limited to a few trials with small participant numbers. Soroksky et $\mathrm{al}^{30}$ found that patients treated with noninvasive ventilation in combination with bronchodilator therapy were less likely to be admitted to hospital compared with those managed with standard therapy alone. NIPPV using high inflation pressures without bronchodilator therapy has been shown to improve lung function (measured by forced expiratory volume in the first second) compared with patients who received bronchodilator therapy alone. ${ }^{31}$ More recently, Gupta et al ${ }^{32}$ demonstrated similar improvements in lung function between NIPPV and standard therapy, with lower bronchodilator requirements and shorter intensive care unit and hospital stay in the NIPPV group. Until larger well designed trials of noninvasive ventilation in asthma exacerbation are available, recommendations for its use in this patient population remain guarded ${ }^{18}$ and are reflected in the infrequent use of noninvasive ventilation for exacerbation of asthma in US emergency departments. ${ }^{33}$

\section{Other causes of acute respiratory failure}

Other potential indications for noninvasive ventilation include hypoxemic respiratory failure, community-acquired pneumonia, ${ }^{34,35}$ and blunt chest trauma, ${ }^{36,37}$ though the relevant trials have been conducted in the intensive care unit as opposed to the emergency department setting. Noninvasive ventilation may be useful in the management of patients with pneumonia but should be used with caution because they may be at higher risk of noninvasive ventilation failure. ${ }^{38}$ Another potential role for noninvasive ventilation in the emergency department setting is as a palliative measure for symptom relief in patients who choose to forego endotracheal intubation and other life support measures. ${ }^{39} \mathrm{In}$ a prospective observational study of mechanical ventilation in four Canadian emergency departments, $20 \%$ of patients who received noninvasive ventilation in the emergency department refused invasive ventilation, $48 \%$ of whom survived to hospital admission. ${ }^{11}$

\section{Use of noninvasive ventilation}

in the prehospital setting

Availability of lightweight portable systems means noninvasive ventilation can now be delivered in the prehospital setting. A recent position statement from the National Association of Emergency Medical Service Physicians ${ }^{40}$ recommends noninvasive ventilation in the prehospital setting for the management of moderate to severe dyspnea and early respiratory failure arising from acute cardiogenic pulmonary edema, COPD, asthma, and pneumonia. Four randomized controlled trials of acute cardiogenic pulmonary edema, ${ }^{41,42}$ COPD,${ }^{43}$ and a mixed population ${ }^{44}$ with small participant numbers suggest that prehospital noninvasive ventilation may achieve a reduction in endotracheal intubation and a mortality benefit. However, despite the recommendation of the National Association of Emergency Medical Service Physicians, the current evidence must be weighed against the significant operational costs associated with prehospital noninvasive ventilation. ${ }^{45}$

\section{Clinical application}

\section{Interfaces}

The delivery of noninvasive ventilation requires an interface that connects the patient to a compressed gas supply delivered either via a ventilator, portable compressor, or flow generator. Oronasal masks that cover the mouth and nose 
are the preferred interface for the management of acute respiratory failure in the emergency department. ${ }^{46}$ Other interface types include nasal masks, nasal pillows, total face masks that seal around the perimeter of the face, and helmets consisting of a transparent plastic hood attached to a soft neck collar. ${ }^{47}$

\section{Ventilator modes and settings}

As stated above, noninvasive ventilation can be delivered as NIPPV or CPAP. NIPPV incorporates inspiratory pressure support (also referred to as inspiratory positive airway pressure) to assist ventilation, and is used in combination with PEEP (also referred to as expiratory positive airway pressure). Inspiratory positive airway pressure generally increases tidal volume in proportion to the amount of pressure applied and is usually set between 8 and $20 \mathrm{~cm} \mathrm{H}_{2} \mathrm{O}$, and expiratory positive airway pressure is set between 4 and $10 \mathrm{~cm} \mathrm{H}_{2} \mathrm{O}$. Selection of pressure settings is based on improved gas exchange and reduced work of breathing while avoiding the increased air leak and discomfort associated with higher pressures. ${ }^{19}$ The difference between inspiratory positive airway pressure and expiratory positive airway pressure is the level of pressure support delivered; this must be taken into consideration when changing expiratory positive airway pressure settings. The terms bilevel positive airway pressure, biphasic positive airway pressure $\left(\mathrm{BiPAP}^{\circledR}\right)$, and noninvasive pressure support ventilation are also used to refer to NIPPV. CPAP does not actively assist inspiration but provides a constant positive airway pressure (generally set between 5 and $15 \mathrm{~cm} \mathrm{H}_{2} \mathrm{O}$ ) throughout inspiration and expiration. ${ }^{48}$ NIPPV requires a specialized ventilation unit to generate inspiratory pressure support, whereas CPAP can be delivered via a flow generator attached to a high flow oxygen outlet in conjunction with a mask fitted with a PEEP valve. Due to the inclusion of inspiratory pressure support, NIPPV will produce greater improvements in oxygenation and respiratory acidosis, as well as decreased work of breathing compared with CPAP. ${ }^{49}$

\section{Monitoring}

Previous consensus conference statements and guidelines indicate that noninvasive ventilation can be delivered in the emergency department depending on staff experience and the availability of resources. ${ }^{29,50}$ Once noninvasive ventilation is commenced, monitoring priorities include response to noninvasive treatment, respiratory and hemodynamic stability, tolerance of ventilation, detection of noninvasive failure, and identification of air leaks around the interface. Physiological measures used to monitor patient response include gas exchange parameters $\left(\mathrm{SpO}_{2}, \mathrm{PaO}_{2}\right)$, ventilatory parameters, and work of breathing ( $\mathrm{pH}$, end tidal $\mathrm{CO}_{2}, \mathrm{PaCo}_{2}$, respiratory rate, accessory muscle use, chest wall motion), level of consciousness, and hemodynamic status (heart rate, blood pressure, capillary refill). Some noninvasive units such as BIPAP Vision (Respironics, Murrayville, PA) enable monitoring of exhaled tidal and minute volume as well as waveform graphics. Published guidelines recommend that arterial blood gas analysis should be performed in the first hour of treatment to gauge patient response. ${ }^{29}$

Dyspnea, ${ }^{51}$ anxiety, ${ }^{52,53}$ and pain scoring tools ${ }^{54}$ may also be useful in assessment of response to and tolerance of noninvasive ventilation. High gas flow in combination with a tight fitting mask may cause claustrophobia and patient discomfort, resulting in poor coordination of respiratory cycling between the patient and the noninvasive ventilation unit. ${ }^{12}$ Tolerance of noninvasive ventilation may be achieved by explanation of the therapy and its benefits, use of an appropriately sized mask, delayed securing of the mask with straps/headgear, and ongoing coaching. Patients should not be left unattended in the initiation and stabilization phases. If a patient is unattended, they must be taught to release the mask from the straps/headgear in the event of vomiting or expectoration of secretions.

\section{Complications of noninvasive ventilation}

Common complications of noninvasive ventilation are listed in Table 1. More serious complications include aspiration pneumonia, pneumothorax, and hemodynamic compromise associated with increased intrathoracic pressures, but frequency rates are less than $5 \% .{ }^{13}$ Ongoing or new onset of rapid shallow breathing, worsening gas exchange, hemodynamic instability, and a decreased level of consciousness are indicative of failure of noninvasive ventilation and the need for intubation.

\section{Invasive ventilation Indications}

Indications for intubation and mechanical ventilation include apnea, lack of airway protection due to decreased level of consciousness, upper airway obstruction or injury, hypoxemic respiratory failure unresponsive to other therapies, hypercapnic respiratory failure unresponsive to other therapies, clinical signs of increased work of breathing and worsening respiratory distress, such as tachypnea, ${ }^{55}$ activation of accessory and expiratory muscles, abnormal 
Table I Complications of noninvasive ventilation

\begin{tabular}{ll}
\hline Complication & Reason for complication \\
\hline $\begin{array}{l}\text { Pressure injury/ulceration } \\
\text { of nose or above ears } \\
\text { Conjunctival irritation }\end{array}$ & Tight fitting mask and head gear \\
Dry mucous membranes & Air leaks around interface \\
Nasal congestion and thick & High flow of dry medical gas \\
secretions & High flow of dry medical gas \\
Gastric distension & Insufflation of air associated \\
Claustrophobia & with high flow \\
Aspiration pneumonia & Tight fitting mask and dyspnea \\
& $\begin{array}{l}\text { Emesis or decreased level of } \\
\text { consciousness resulting in loss } \\
\text { of airway reflexes }\end{array}$ \\
Hemodynamic compromise & $\begin{array}{l}\text { Increased intrathoracic pressure } \\
\text { causing decreased venous return }\end{array}$ \\
Increased intrathoracic pressure
\end{tabular}

chest wall movements ${ }^{56}$ tachycardia, and hypertension. As discussed above, noninvasive ventilation is an appropriate first-line treatment in the management of hypoxemic or hypercapnic respiratory failure in patients with acute cardiogenic pulmonary edema or COPD.

\section{Clinical application}

Since its introduction in the 1960s, positive pressure ventilators have undergone a continuous evolution, with the advent of new modes and features that may challenge clinicians' understanding of the technology, particularly in the emergency department setting where exposure to ventilated patients may be variable. A comprehensive description of ventilator modes, settings, and applications is beyond the scope of this review. However, emergency department clinicians managing ventilated patients should have sufficient knowledge so that injurious ventilation is not applied.

Ventilator modes describe how the ventilator controls pressure, volume, and flow during a breath and describes how breaths are sequenced..$^{57}$ Each breath is triggered (started) either by the patient or by the ventilator. During inspiration, breath size is limited to a set target of pressure, volume, or flow which cannot be exceeded. At the end of inspiration, the cycling variable, ie, pressure, flow, volume, or time, determines the end of the inspiratory phase. Breath sequencing refers to the sequencing of mandatory and spontaneous breaths. Mandatory breaths are either triggered or cycled by the ventilator. ${ }^{58}$ Spontaneous breaths are both started (triggered) and stopped (cycled) by the patient. Spontaneous breaths may be assisted by the ventilator to achieve a set volume or pressure. Table 2 describes the features of five common ventilator modes.

Regardless of the mode selected, injurious ventilation should be avoided. A landmark international, multicenter, randomized controlled trial demonstrated a mortality benefit for patients with acute respiratory distress syndrome using a ventilation strategy of tidal volumes set at $\leq 6 \mathrm{~mL}$ per kg of predicted body weight while targeting a plateau pressure of $<30 \mathrm{~cm} \mathrm{H}_{2} \mathrm{O}$ compared with a tidal volume of $12 \mathrm{~mL} / \mathrm{kg} .{ }^{59}$ More recently, a randomized controlled trial comparing tidal volumes of $6-10 \mathrm{~mL} / \mathrm{kg}$ of predicted body weight in patients without acute lung injury at the onset of ventilation reported increased development of acute lung injury in the $10 \mathrm{~mL} / \mathrm{kg}$ group. ${ }^{60}$ This style of lungprotective ventilation may be delivered by close monitoring of plateau pressure with a volume-control mode such as

Table 2 Common ventilator modes

\begin{tabular}{|c|c|c|}
\hline Mode & Description & Clinical implications \\
\hline $\begin{array}{l}\text { Controlled mechanical } \\
\text { ventilation }\end{array}$ & $\begin{array}{l}\text { All breaths are mandatory, no patient triggering is enabled. } \\
\text { Also called volume-controlled ventilation (volume-targeted) } \\
\text { and pressure-controlled ventilation (pressure-targeted) }\end{array}$ & $\begin{array}{l}\text { Patients with respiratory effort require sedation } \\
\text { and neuromuscular blockade. Risk of respiratory } \\
\text { muscle atrophy due to disuse }\end{array}$ \\
\hline Assist-control & $\begin{array}{l}\text { Breaths may be either machine or patient triggered but all } \\
\text { are cycled by the ventilator. Assist control may be } \\
\text { delivered as volume-targeted or pressure-targeted }\end{array}$ & $\begin{array}{l}\text { Activation of the diaphragm with patient triggering. } \\
\text { Risk of respiratory alkalosis if tachypnea develops }\end{array}$ \\
\hline $\begin{array}{l}\text { Synchronized intermittent } \\
\text { mandatory ventilation }\end{array}$ & $\begin{array}{l}\text { Mandatory breaths are delivered using a set rate and } \\
\text { volume or pressure. Mandatory breaths are synchronized } \\
\text { with patient triggers within a timing window. Between } \\
\text { mandatory breaths the patient can breathe spontaneously }\end{array}$ & $\begin{array}{l}\text { Reduced need for sedation. Activation } \\
\text { of the diaphragm with patient triggering }\end{array}$ \\
\hline $\begin{array}{l}\text { Pressure support } \\
\text { ventilation }\end{array}$ & $\begin{array}{l}\text { All breaths are patient triggered and cycled. } \\
\text { Pressure applied by the ventilator during inspiration } \\
\text { (pressure support) augments patient effort }\end{array}$ & $\begin{array}{l}\text { Reduced need for sedation. Facilitates ventilator } \\
\text { weaning. Level of pressure support can be adjusted } \\
\text { to achieve desired tidal volume. Sustains respiratory } \\
\text { muscle tone and decreases work of breathing }\end{array}$ \\
\hline $\begin{array}{l}\text { Continuous positive } \\
\text { airway pressure }\end{array}$ & $\begin{array}{l}\text { All breaths are patient triggered and cycled. } \\
\text { Positive pressure is applied throughout inspiratory } \\
\text { and expiratory phases of the respiratory cycle }\end{array}$ & $\begin{array}{l}\text { Requires intact respiratory drive and patient } \\
\text { ability to maintain adequate tidal volumes }\end{array}$ \\
\hline
\end{tabular}


assist control (volume control), or using pressure-control ventilation with titration of inspiratory pressure to achieve $6 \mathrm{~mL} / \mathrm{kg}$ of predicted body weight. Volume-control ventilation enables easy regulation of minute ventilation and $\mathrm{CO}_{2}$, but does not provide control over peak airway pressures, so careful monitoring is required to avoid injurious pressures. In contrast, pressure-control ventilation allows control over peak inspiratory pressures and inspiratory time, but does not guarantee tidal volumes. Another important consideration for tidal volume selection is the correct calculation of predicted body weight. Lung size correlates with lean body mass, which is a function of height and not actual body weight. ${ }^{61}$ Unfortunately, tidal volume targets are often determined using clinician estimation of ideal or actual body weight, which is generally inaccurate and leads to excessive volumes. ${ }^{62}$ To assist with appropriate selection of tidal volumes, the ARDSnet group provide tables of predicted body weight and tidal volume for males and females ${ }^{63}$ that can be made readily available on ventilators or emergency department bays used for ventilated patients.

Low volume, pressure-targeted strategies alone may be insufficient to limit lung injury. ${ }^{64}$ Zero or low PEEP may cause lung injury due to cyclic opening and closing of alveoli. ${ }^{65}$ PEEP prevents alveolar collapse, increases residual lung volume, and thereby recruit collapsed alveoli, improving ventilation/perfusion (V/Q) match and enhancing movement of fluid out of the alveoli. ${ }^{66}$ Though the optimal PEEP setting in patients with acute respiratory distress syndrome remains controversial, a PEEP of 5-10 $\mathrm{cm} \mathrm{H}_{2} \mathrm{O}$ is generally safe and acceptable for most patient presentations in the emergency department.

\section{Monitoring}

Monitoring of the ventilated patient should focus on assessment of patient response to and titration of mechanical ventilation and other interventions, while avoiding complications. Appropriate staffing ratios of clinicians with experience in the management of ventilated patients are essential to ensure patient safety. Pulse oximetry, continuous heart rate, and frequent blood pressure monitoring are minimum monitoring requirements. End-tidal $\mathrm{CO}_{2}$ monitoring should be used to confirm endotracheal tube placement during all intubations, ${ }^{67,68}$ and to detect endotracheal tube migration and integrity of the ventilator circuit during transport. ${ }^{69}$ End-tidal $\mathrm{CO}_{2}$ is also useful in identifying hyperventilation and hypoventilation in patients with traumatic brain injury, both of which should be avoided due to potential adverse outcomes. ${ }^{70}$ During pressure-control ventilation, end-tidal $\mathrm{CO}_{2}$ monitoring is useful in detecting changes in minute ventilation due to alterations in airway resistance and dynamic compliance. Arterial blood gas analysis should be used when possible to quantitate response to therapeutic interventions, such as mechanical ventilation. ${ }^{71}$

\section{Ventilator alarms and graphics}

All mechanical ventilators are equipped with alarms designed to detect technical events such as patient disconnection from the ventilator (low inspiratory pressure) and changes in patient status. Alarms should be set so that they appropriately alert clinicians to evaluate the patient and ventilator and do not result in alarm fatigue. ${ }^{72}$ High-pressure alarms indicate changes in resistance to gas flow due to airflow obstruction and decreased lung compliance. Airflow obstruction may result from airway secretions, bronchospasm, endotracheal tube migration, kinking of the ventilator circuit, and biting on the endotracheal tube. Decreased pulmonary compliance may be as a result of atelectasis, pulmonary edema, pneumonia, pneumothorax, and pulmonary fibrosis. Minute ventilation, tidal volume, and apnea alarms alert clinicians to changes in a patient's respiratory rate and tidal volume that warrant further investigation.

Ventilator graphics may be available on more advanced ventilators used in the emergency department. These assist with assessment of patient-ventilator synchrony, patient triggering, appropriateness of inspiratory/expiratory times, presence of gas trapping, appropriateness and adequacy of flow, lung compliance, airway resistance, and circuit leaks. ${ }^{73,74}$ The pressure-time scalar (pressure on $\mathrm{x}$ axis and time on $y$ axis) reflects airway pressure during inspiration and expiration and can be used to evaluate peak, plateau, and end inspiratory pressures, inspiratory and expiratory times, appropriateness of flow, and patient-ventilator synchrony. The flow-time scalar assists with detection of gas trapping as well as response to bronchodilators. In the absence of gas trapping, the expiratory limb drops sharply below baseline then gradually returns to zero before the next breath. Gas trapping is indicated by failure to return to baseline before the next inspiratory phase. Gas trapping may occur with airflow limitation in association with COPD and asthma. Consequences of gas trapping include dynamic hyperinflation, reduced respiratory compliance, respiratory muscle fatigue, and hemodynamic compromise. ${ }^{75}$

\section{Analgesia and sedation}

Frequently critically ill patients require analgesia and sedation for management of pain and anxiety associated with their 
presenting condition as well as to facilitate tolerance of lifesupporting technology including mechanical ventilation. ${ }^{76}$ Adequate provision of analgesia for ventilated patients unable to communicate due to sedation, altered level of consciousness, and endotracheal intubation is challenging and often inadequate in both emergency department and intensive care unit settings. ${ }^{77,78}$ Sedative agents may be administered more frequently than analgesia in the emergency department, ${ }^{79}$ but professional society guidelines recommend sedation in ventilated patients should be commenced only after provision of adequate analgesia. ${ }^{76}$ Various tools are now available to assess pain ${ }^{80,81}$ in patients unable to communicate and sedation level, ${ }^{82,83}$ and can be used in the emergency department setting. Behaviors such as facial grimacing, wincing, guarding, and restlessness are also recognized indicators of pain $^{84}$ and should be monitored. Physiological indicators such as blood pressure, respiratory rate, and heart rate, lack specificity for pain, ${ }^{85}$ and therefore should serve as a stimulus for further assessment of behavioral pain indicators and analgesic management and not as an independent marker of the presence of pain. ${ }^{86}$

Oversedation should be avoided in the intubated, ventilated patient due to the potential for increased duration of ventilation and adverse consequences, including delirium, delayed mobilization, persistent psychological dysfunction, and cognitive impairment. ${ }^{87-89}$ Sedative administration strategies that potentially reduce oversedation include use of: agents such as propofol with ultrashort therapeutic halflives, intermittent bolus dosing versus continuous infusions, sedation protocols with sedation titrated to a sedation score, ${ }^{90}$ and daily sedative interruption..$^{91}$ One randomized controlled trial comparing propofol infusion with intermittent bolus doses of lorazepam demonstrated fewer median ventilator days in the infusion arm, ${ }^{92}$ but different pharmacokinetic, pharmacodynamic, and bioaccumulation profiles of these two drugs makes interpretation difficult. Adverse events related to sedation and analgesia occur more frequently in the intensive care unit than in the emergency department due to administration of higher doses for prolonged periods. ${ }^{93}$ However, emergency department clinicians should be aware of interventions to facilitate appropriate sedation, particularly for ventilated patients with a prolonged emergency department stay.

\section{Positioning}

Frequent repositioning of ventilated patients is essential for prevention of atelectasis and maintenance of skin integrity. Due to the risk of ventilator-associated pneumonia associated with aspiration of abnormally colonized oropharyngeal and gastric contents, ${ }^{94,95}$ semirecumbent positioning with head of bed elevation between 30 and 45 degrees is recommended in numerous guidelines and care bundles. ${ }^{96,97}$ Because supine positioning within the first 24 hours of ventilation has been shown to be a risk factor for ventilatorassociated pneumonia, ${ }^{98}$ emergency department clinicians should be mindful to employ semirecumbent positioning at every opportunity in patients without contraindications. Contraindications relevant to the emergency department setting include suspected or existing spinal injury, intracranial hypertension (for 45 degree head of bed elevation), unstable pelvic fractures, and large abdominal wounds. Given that some degree of semirecumbent position is preferable, patients with contraindications can have their head elevated by tilting the whole bed.

\section{Cuff pressure}

Endotracheal tubes have a balloon-like cuff that circumferentially surrounds the lower exterior portion of the tube to facilitate delivery of positive pressure ventilation without loss of tidal volume and to prevent aspiration of oropharyngeal contents. ${ }^{99}$ Appropriate cuff inflation is required at all times to prevent bronchial aspiration of secretions ${ }^{100}$ that may lead to ventilator-associated pneumonia. ${ }^{101-104}$ Cuff pressure monitoring using a pressure manometer during the inspiratory phase ${ }^{105}$ provides an objective estimate of cuff pressure that does not involve cuff deflation. Cuff pressure should be maintained at $20-30 \mathrm{~cm} \mathrm{H}_{2} \mathrm{O}$, assessed after intubation as soon as practicable, and reassessed at four-hourly intervals due to the potential for pressure to decrease over time and alter due to tube migration, coughing, and changes in lung compliance, airway, and intrathoracic pressures. ${ }^{99,105,106}$

\section{Complications}

Initiation of positive pressure ventilation may result in transient hypotension due to insufficient venous return. ${ }^{107}$ Ventilator-associated lung injury may occur in both injured and healthy lungs by perpetuating alveolar and systemic inflammatory response systems through alveolar overdistension and cyclic opening and closing. ${ }^{108-111}$ Barotrauma due to excessive peak inspiratory pressures may result in extra-alveolar gas causing pneumothorax or subcutaneous emphysema. As discussed above, ventilatorassociated pneumonia is a frequent and potentially deadly complication of mechanical ventilation that may be prevented by appropriate positioning and endotracheal cuff inflation. Regular oral care with $2 \%$ chlorhexidine antiseptic also has been shown to reduce ventilator-associated pneumonia 


\section{Table 3 Complications of invasive ventilation}

Barotrauma: pneumothorax, pneumomediastinum, pneumopericardium, pulmonary interstitial emphysema, subcutaneous emphysema

Volutrauma: shearing stress, endothelial and epithelial cell injury, fluid retention and pulmonary edema, perivascular and alveolar hemorrhage, alveolar rupture

Biotrauma: activation of systemic and local inflammatory mechanisms Ventilation/perfusion mismatch: alveolar distension causes compression of the adjacent pulmonary capillaries resulting in dead space ventilation $\downarrow$ cardiac output due to $\uparrow$ intrathoracic pressure resulting in hypotension, $\downarrow$ cerebral perfusion pressure, and decreased renal and hepatic blood flow

$\uparrow$ right ventricular afterload due to $\uparrow$ intrathoracic pressure. May result in $\downarrow$ left ventricular compliance and preload

$\downarrow$ urine output due to $\downarrow$ glomerular filtration rate, $\uparrow$ sodium reabsorption and activation of the renin-angiotensin-aldosterone system Fluid retention: due to above renal factors as well as $\uparrow$ antidiuretic hormone and $\downarrow$ atrial natriuretic peptide

Impaired hepatic function: due to $\uparrow$ pressure in the portal vein,

$\downarrow$ portal venous blood flow, $\downarrow$ hepatic vein blood flow

$\uparrow$ intracranial pressure: due to $\downarrow$ cerebral venous outflow

Oxygen toxicity resulting in alterations to lung parenchyma similar to those found in acute respiratory distress syndrome

Pulmonary emboli and deep vein thrombosis due to immobility

lleus, diarrhea due to alterations in gastric motility

Gastrointestinal hemorrhage, gastritis and ulceration due to stress, anxiety and critical illness

Pain, anxiety, agitation, and delirium due to critical illness and associated interventions

Neuropathies and myopathies develop in association with critical illness, corticosteroids, and neuromuscular blockade

rates and should be considered for all intubated patients. ${ }^{112}$ Development of auto PEEP and hyperinflation are common complications in patients with increased airway resistance, such as in COPD and asthma. Ventilatory strategies to reduce hyperinflation include reduction of respiratory rate and tidal volume and prolongation of expiratory times. ${ }^{113}$ Additional complications associated with mechanical ventilation are listed in Table 3.

\section{Conclusion}

Critically ill patients requiring noninvasive or invasive ventilation often present to emergency departments, and due to hospital crowding and constrained critical care services, may remain in the emergency department for a prolonged duration. Compared with their intensive care unit counterparts, emergency department clinicians may have variable exposure to management of this patient population and may lack knowledge and expertise, particularly in their longitudinal management beyond initial stabilization. This review has discussed several key aspects of management of noninvasive and invasive ventilation, with a particular emphasis on initiation and ongoing monitoring priorities, and focused on maintaining patient safety and improving patient outcomes.

\section{Disclosure}

The author reports no conflicts of interest in this work.

\section{References}

1. Ghosh R, Pepe P. The critical care cascade: a systems approach. Curr Opin Crit Care. 2009;15:279-283.

2. Fromm R, Gibbs L, McCullum W, et al. Critical care in the emergency department: a time-based study. Crit Care Med. 1993;21:970-976.

3. Varon J, Fromm R, Levine R. Emergency department procedures and length of stay for critically ill medical patients. Ann Emerg Med. 1994;23:546-549

4. Clark K, Mnormile L. Delays in implementing admission orders for critical care patients associated with length of stay in emergency departments in six mid-atlantic states. J Emerg Nurs. 2002;28: 489-495.

5. Dent A, Weiland T, Paltridge D. Australasian emergency physicians; a learning and educational needs analysis. Part Four: CPD topics desired by emergency physicians. Emerg Med Aust. 2008;20:260-266.

6. Lambe S, Washington D, Fink A, et al. Trends in the use and capacity of California's emergency departments 1990-1999. Ann Emerg Med. 2002;39:389-396.

7. Herring A, Wilper A, Himmelstein D, et al. Increasing length of stay among adult visits to US emergency departments, 2001-2005. Acad Emerg Med. 2009;16:609-616.

8. McCaig L. National Hospital Ambulatory Medical Care Survey: 2002 emergency department summary. Adv Data. 2004;340:1-34.

9. Nelson M, Waldrop R, Jones J, Randall Z. Critical care provided in an urban emergency department. Am J Emerg Med. 1998;16:56-59.

10. Green R, MacIntyre J. Critical care in the emergency department: an assessment of the length of stay and invasive procedures performed on critically ill ED patients. Scand J Trauma Resusc Emerg Med. 2009; $17: 47$

11. Rose L, Gray S, Atzema C, et al. Mechanical ventilation in the emergency department: a prospective observational pilot study. Acad Emerg Med. 2011;18:S208.

12. Mehta S, Hill N. Noninvasive ventilation: state of the art. Am J Respir Crit Care Med. 2001;163:540-577.

13. Hill N. Noninvasive positive pressure ventilation. In: Tobin M, editor. Principles and Practice of Mechanical Ventilation. New York, NY: McGraw-Hill; 2006.

14. Hill N, Brennan J, Garpestad E, Nava S. Noninvasive ventilation in acute respiratory failure. Crit Care Med. 2007;35:2402-2407.

15. Kaye D, Mansfield D, Naughton MT. Continuous positive airway pressure decreases myocardial oxygen consumption in heart failure. Clin Sci. 2004;106:599-603.

16. Naughton M, Rahman M, Hara K, Floras J, Bradley T. Effect of continuous positive airway pressure on intrathoracic and left ventricular transmural pressures in patients with congestive heart failure. Circulation. 1995;91:1725-1731.

17. Penuelas O, Frutos-Vivar F, Esteban A. Noninvasive positive-pressure ventilation in acute respiratory failure. Can Med Assoc J. 2007;177: $1211-1218$

18. Keenan S, Sinuff T, Burns K, et al. Clinical practice guidelines for the use of noninvasive positive-pressure ventilation and noninvasive continuous positive airway pressure in the acute care setting. CMAJ. 2011;183:E195-E214.

19. Confalonieri M, Garuti G, Cattaruzza M, et al. A chart of failure risk for noninvasive ventilation in patients with COPD exacerbation. Eur Respir J. 2005;25:348-355. 
20. Masip J, Roque M, Sanchez B, Ferandez R, Subirana M, Exposito J. Noninvasive ventilation in acute cardiogenic pulmonary edema. JAMA. 2005;294:3124-3130.

21. Peter JV, Moran JL, Phillips-Hughes J, Graham P, Bersten AD. Effect of non-invasive positive pressure ventilation (NIPPV) on mortality in patients with acute cardiogenic pulmonary oedema: a meta-analysis. Lancet. 2006;367:1155-1163.

22. Winck JC, Azevedo LF, Costa-Pereira A, Antonelli M, Wyatt JC. Efficacy and safety of non-invasive ventilation in the treatment of acute cardiogenic pulmonary edema - a systematic review and meta-analysis. Crit Care. 2006;10:R69.

23. Collins S, Mielniczuk L, Whittingham H, Boseley M, Schramm D, Storrow A. The use of noninvasive ventilation in emergency department patients with acute cardiogenic pulmonary edema: a systematic review. Ann Emerg Med. 2006;48:260-269.

24. Ho KM, Wong K. A comparison of continuous and bi-level positive airway pressure non-invasive ventilation in patients with acute cardiogenic pulmonary oedema: a meta-analysis. Crit Care. 2006;10(2):R49.

25. Vital F, Saconato H, Ladeira M, et al. Non-invasive positive pressure ventilation (CPAP or bilevel NPPV) for cardiogenic pulmonary edema. Cochrane Database Syst Rev. 2008;3:CD005351.

26. Gray A, Goodacre S, Newby D, et al; 3CPO Study Investigators. A multicentre randomised controlled trial of the use of continuous positive airway pressure and non-invasive positive pressure ventilation in the early treatment of patients presenting to the emergency department with severe acute cardiogenic pulmonary oedema: the $3 \mathrm{CPO}$ trial. Health Technol Assess. 2009;13:1-106.

27. Weng C, Zhao Y, Liu Q, et al. Meta-analysis: Noninvasive ventilation in acute cardiogenic pulmonary edema. Ann Intern Med. 2010;152: 590-600.

28. Mehta S, Jay GD, Woolard RH, et al. Randomized, prospective trial of bilevel versus continuous positive airway pressure in acute pulmonary edema. Crit Care Med. 1997;25:620-628.

29. British Thoracic Society Standards of Care Committee. Non-invasive ventilation in acute respiratory failure. Thorax. 2002;57:192-211.

30. Soroksky A, Stav D, Shpirer I. A pilot prospective, randomized, placebocontrolled trial of bilevel positive airway pressure in acute asthmatic attack. Chest. 2003;123:1018-1025.

31. Soma T, Hino M, Kida K, Kudoh S. A prospective and randomized study for improvement of acute asthma by non-invasive positive pressure ventilation. Intern Med. 2008;47:493-501.

32. Gupta D, Nath A, Agarwal R, Behera D. A prospective randomized controlled trial on the efficacy of noninvasive ventilation in severe acute asthma. Respir Care. 2010;55:536-543.

33. Hess D, Pang J, Camargo C. A survey of the use of noninvasive ventilation in academic emergency departments in the United States. Respir Care. 2009;54:1306-1312.

34. Confalonieri M, Potena A, Carbone G, Della Porta R, Tolley E, Meduri G. Acute respiratory failure in patients with severe community-acquired pneumonia. Am J Respir Crit Care Med. 1999;160:1585-1591.

35. Ferrer M, Esquinas A, Leon M, Gonzalez G, Alarcon A, Torres A. Noninvasive ventilation in severe hypoxemic respiratory failure: a randomized clinical trial. Am J Respir Crit Care Med. 2003;168 1438-1444.

36. Gunduz $\mathrm{M}$, Unlugenc $\mathrm{H}$, Ozalevli $\mathrm{M}$, Inanoglu $\mathrm{K}$, Akman $\mathrm{H}$. A comparative study of continuous positive airway pressure (CPAP) and intermittent positive pressure ventilation (IPPV) in patients with flail chest. Emerg Med J. 2005;22:325-329.

37. Hernandez G, Fernandez R, Lopez-Reina P, et al. Noninvasive ventilation reduces intubation in chest trauma-related hypoxemia: a randomized clinical trial. Chest. 2010;137:74-80.

38. Antonelli M, Conti G, Moro M, et al. Predictors of failure of noninvasive positive pressure ventilation in patients with acute hypoxemic respiratory failure; a multi-center study. Intensive Care Med. 2001;27:1718-1728.

39. Clini EM, Ambrosino N. Nonpharmacological treatment and relief of symptoms in COPD. Eur Respir J. 2008;32:218-228.
40. Daily J, Wang H. Noninvasive positive pressure ventilation: resource document for the National Association of EMS Physicians position statement. Prehosp Emerg Care. 2011;15:432-438.

41. Plaisance P, Pirracchio R, Berton C, Vicaut E, Payen D. A randomized study of out-of-hospital continuous positive airway pressure for acute cardiogenic pulmonary oedema: physiological and clinical effects. Eur Heart J. 2007;28:2895-2901.

42. Weitz G, Struck J, Zonak A, Balnus S, Perras B, Dodt C. Prehospital noninvasive pressure support ventilation for acute cardiogenic pulmonary edema. Eur J Emerg Med. 2007;14:276-279.

43. Schmidbauer W, Ahlers O, Spies C, Dreyer A, Mager G, Kerner T. Early prehospital use of non-invasive ventilation improves acute respiratory failure in acute exacerbation of chronic obstructive pulmonary disease. Emerg Med J. 2011;28:626-627.

44. Thompson J, Petrie D, Ackroyd-Stolarz S, Bardua D. Out-of-hospital continuous positive airway pressure ventilation versus usual care in acute respiratory failure: a randomized controlled trial. Ann Emerg Med. 2008;52:232-241.

45. Taylor DM, Bernard SA, Masci K, MacBean CE, Kennedy MP, Zalstein S. Prehospital noninvasive ventilation: a viable treatment option in the urban setting. Prehosp Emerg Care. 2008;12:42-45.

46. Maheshwari V, Paioli D, Rothaar R, Hill N. Utilization of noninvasive ventilation in acute care hospitals: a regional survey. Chest. 2006;129:1226-1233.

47. Pelosi P, Severgnini P, Aspesi M, et al. Non-invasive ventilation delivered by conventional interfaces and helmet in the emergency department. Eur J Emerg Med. 2003;10:79-86.

48. Nava S, Hill N. Non-invasive ventilation in acute respiratory failure. Lancet. 2009;374:250-259.

49. Chadda K, Annane D, Hart N, Gajdos P, Raphaël J, Lofaso F. Cardiac and respiratory effects of continuous positive airway pressure and noninvasive ventilation in acute cardiac pulmonary edema. Crit Care Med. 2002;30:2457-2461.

50. Evans T. International Consensus Conferences in Intensive Care Medicine: non-invasive positive pressure ventilation in acute respiratory failure. Intensive Care Med. 2001;27:166-178.

51. Borg G. Psychophysical bases of perceived exertion. Med Sci Sports Exerc. 1982;14:377-381.

52. McKinley S, Stein-Parbury J, Chehelnabi A, Lovas J. Assessment of anxiety in intensive care patients by using the faces anxiety scale. Am J Crit Care. 2004;13:146-152.

53. De Jong M, An K, McKinley S, Garvin B, Hall L, Moser D. Using a 0-10 scale for assessment of anxiety in patients with acute myocardial infarction. Dimens Crit Care Nurs. 2005;24:139-146.

54. Jensen M, Karoly P, Braver S. The measurement of clinical pain intensity: a comparison of six methods. Pain. 1986;27:117-126.

55. Laghi F, Tobin M. Indications for mechanical ventilation. In: Tobin M, editor. Principles and Practice of Mechanical Ventilation. 2nd ed. New York, NY: McGraw-Hill; 2006.

56. Tobin M, Guenther S, Perez W, et al. Konno-Mead analysis of ribcage-abdominal motion during successful and unsuccessful trials of weaning from mechanical ventilation. Am Rev Respir Dis. 1987;135:1320-1328.

57. Chatburn R. Classification of ventilator modes: update and proposal for implementation. Respir Care. 2007;52:301-323.

58. Chatburn R. Understanding mechanical ventilators. Expert Rev Respir Med. 2010;4:809-819.

59. ARDSnet. Ventilation with lower tidal volumes compared with traditional tidal volumes for acute lung injury and the acute respiratory distress syndrome. $N$ Engl J Med. 2000;342:1301-1308.

60. Determann R, Royakkers A, Wolthuis E, et al. Ventilation with lower tidal volumes as compared with conventional tidal volumes for patients without acute lung injury: a preventive randomized controlled trial. Crit Care Med. 2010;14:R1.

61. Stehman C, Buckley R, Dos Santos F, et al. Bedside estimation of patient height for calculating ideal body weight in the emergency department. J Emerg Med. 2011;41:97-101. 
62. Diacon A, Koegelenberg C, Klüsmann K, Bolliger C. Challenges in the estimation of tidal volume settings in critical care units. Intensive Care Med. 2006;32:1670-1671.

63. NHLBI ARDS Network. Predicted body weight calculator. Available from: http://www.ardsnet.org/node/77460. Accessed February 14, 2011.

64. Lapinsky SE, Mehta S. Bench-to-bedside review: recruitment and recruiting maneuvers. Crit Care. 2005;9:60-64.

65. Muscedere J, Mullen J, Gan K, Slutsky A. Tidal ventilation at low airway pressures can augment lung injury. Am J Respir Crit Care Med. 1994;149:1327-1334.

66. Kallet R. Evidence-based management of acute lung injury and acute respiratory distress syndrome. Respir Care. 2004;49:793-809.

67. Cummins R, Hazinski M. Guidelines based on the principle 'First, do no harm'. New guidelines on tracheal tube confirmation and prevention of dislodgment. Resuscitation. 2000;46:443-447.

68. Deakin C, Morrison L, Morley P, et al. Part 8: Advanced life support: 2010 international consensus on cardiopulmonary resuscitation and emergency cardiovascular care science with treatment recommendations. Resuscitation. 2010;81:e93-e174.

69. Donald M, Paterson B. End tidal carbon dioxide monitoring in prehospital and retrieval medicine: a review. Emerg Med J. 2006;23: 728-730.

70. Davis D. Early ventilation in traumatic brain injury. Resuscitation. 2008;76:333-340.

71. Blonshine S, Foss C, Mottram C, Ruppal G, Wagner J. Blood gas analysis and hemoximetry: 2001 revision and update. Respir Care. 2001; 46:498-505.

72. Hannibal G. Monitor alarms and alarm fatigue. AACN Adv Crit Care. 2011;22:418-420.

73. Burns S. Working with respiratory waveforms: how to use bedside graphics. AACN Clin Issues. 2003;14:133-144.

74. Rittner F, Doring M. Curves and loops in mechanical ventilation. Hong Kong: Draeger Medical Asia Pacific.

75. Blanch L, Bernabé F, Lucangelo U. Measurement of air trapping, intrinsic positive end-expiratory pressure, and dynamic hyperinflation in mechanically ventilated patients. Respir Care. 2005;50:110-123.

76. Jacobi J, Frase G, Coursin D, et al. Clinical practice guidelines for the sustained use of sedatives and analgesics in the critically ill adult. Crit Care Med. 2002;30:119-141.

77. Bonomo J, Butler A, Lindsell C, Venkat A. Inadequate provision of postintubation anxiolysis and analgesia in the ED. Am J Emerg Med. 2008;26:469-472.

78. Payen J-F, Chanques G, Mantz J, et al. Current practices in sedation and analgesia for mechanically ventilated critically ill patients. Anesthesiology. 2007;106:687-695.

79. Rose L, Gerdtz M. Use of invasive mechanical ventilation in Australian emergency departments. Emerg Med Aust. 2009;21:108-116.

80. Gelinas C, Fillion L, Puntillo KA, Viens C, Fortier M. Validation of the critical-care pain observation tool in adult patients. Am J Crit Care. 2006; $15: 420-427$

81. Payen J-F, Bru O, Bosson J-L, et al. Assessing pain in critically ill sedated patients by using a behavioral pain scale. Crit Care Med. 2001;29:2258-2263.

82. Riker R, Picard J, Fraser G. Prospective evaluation of the sedationagitation scale for adult critically ill patients. Crit Care Med. 1999; 27:1325-1329.

83. Sessler C, Gosnell M, Grap M, et al. The Richmond agitation-sedation scale: validity and reliability in adult intensive care unit patients. Am J Respir Crit Care Med. 2002;166:1338-1344.

84. Puntillo KA, Morris AB, Thompson CL, Stanik-Hutt J, White CA, Wild LR. Pain behaviors observed during six common procedures: results from Thunder Project II. Crit Care Med. 2004;32:421-427.

85. Young J, Siffleet J, Nikoletti S, Shaw T. Use of a behavioural pain scale to assess pain in ventilated, unconscious and/or sedated patients. Intensive Crit Care Nurs. 2006;22:32-39.
86. Herr K, Coyne P, Key T, et al. Pain assessment in the nonverbal patient: position statement with clinical practice recommendations. Pain Management Nurs. 2006;7:44-52.

87. Girard T, Kress J, Fuchs B, et al. Efficacy and safety of a paired sedation and ventilator weaning protocol for mechanically ventilated patients in intensive care (awakening and breathing controlled trial): a randomised controlled trial. Lancet. 2008;371: 126-134.

88. Girard T, Jackson J, Pandharipande P, et al. Delirium as a predictor of long-term cognitive impairment in survivors of critical illness. Crit Care Med. 2010;38:1513-1520.

89. Kress JP, Gehlbach B, Lacy M, Pliskin N, Pohlman AS, Hall JB. The long-term psychological effects of daily sedative interruption on critically ill patients. Am J Respir Crit Care Med. 2003;168: 1457-1461.

90. Brook A, Ahrens T, Schaiff R, et al. Effect of a nursing-implemented sedation protocol on the duration of mechanical ventilation. Crit Care Med. 1999;27:2609-2615.

91. Kress JP, Pohlman AS, O’Connor MF, Hall JB. Daily interruption of sedative infusions in critically ill patients undergoing mechanical ventilation. $N$ Engl J Med. 2000;342:1471-1477.

92. Carson SS, Kress JP, Rodgers JE, et al. A randomized trial of intermittent lorazepam versus propofol with daily interruption in mechanically ventilated patients. Crit Care Med. 2006;34:1326-1332.

93. Devlin J, Mallow-Corbett S, Riker R. Adverse drug events associated with the use of analgesics, sedatives, and antipsychotics in the intensive care unit. Crit Care Med. 2010;38:S231-S243.

94. Orozco-Levi M, Torres A, Ferrer M, et al. Semirecumbent position protects from pulmonary aspiration but not completely from gastroesophageal reflux in mechanically ventilated patients. Am J Respir Crit Care. 1995;152:1387-1390.

95. Torres A, Serra-Battlles J, Ros E, et al. Pulmonary aspiration of gastric contents in patients receiving mechanical ventilation: the effect of body position. Ann Intern Med. 1992;116:540-543.

96. Muscedere J, Dodek P, Keenan S, Fowler R, Cook D, Heyland D. Comprehensive evidence-based clinical practice guidelines for ventilator-associated pneumonia: prevention. J Crit Care. 2008; 23:126-137.

97. Tablan O, Anderson L, Besser R, Bridges C, Hajjeh R. Guidelines for prevention of health care-associated pneumonia, 2003: recommendations of the $\mathrm{CDC}$ and the Healthcare Infection Control Practices Advisory Committee. MMWR Recomm Rep. 2004;53: $1-36$.

98. Kollef M. Ventilator-associated pneumonia: a multivariate analysis. JAMA. 1993;270:1965-1970.

99. Pierce L. Management of the Mechanically Ventilated Patient. 2nd ed, St Louis, MO: Saunders Elsevier; 2007.

100. Diaz E, Rodriguez A. Ventilator-associated pneumonia: issues related to the artificial airway. Respir Care. 2005;50:906-909.

101. Baxter A, Allan J, Bedard J, et al. Adherences to simple and effective measures reduces the incidence of ventilator-associated pneumonia. Can J Anaesth. 2005;52:535-541.

102. Sole M, Byers J, Ludy J, Ostrow L. Suctioning techniques and airway management practices: pilot study and instrument evaluation. Am J Crit Care. 2002;11:363-368.

103. Cook D, DeJonghe B, Brochard L, Brun-Buisson C. Influence of airway management on ventilator-associated pneumonia. JAMA. 1998;279:781-787.

104. Sengupta P, Sessler D, Maglinger P, et al. Endotracheal tube cuff pressure in three hospitals and the volume required to produce an appropriate cuff pressure. BMC Anesthesiol . 2004;4:4-8.

105. Vyas D, Inweregbu K, Pittard A. Measurement of tracheal tube cuff pressure in critical care. Anaesthesia. 2002;57:275-277.

106. Cremlisk J, Horn M, Wilson D, Marino B. Artificial airways: a survey of cuff management practices. Heart Lung. 1996;25: $225-235$. 
107. Manthous C. Avoiding circulatory complications during endotracheal intubation and initiation of positive pressure ventilation. J Emerg Med. 2010;38:622-631.

108. Gajic O, Saqib I, Mendez J, et al. Ventilator-associated lung injury in patients without acute lung injury at the onset of mechanical ventilation. Crit Care Med. 2004;32:1817-1824.

109. Gattinoni L, Caironi P, Carlesso E. How to ventilate patients with acute lung injury and acute respiratory distress syndrome. Curr Opin Crit Care. 2005;11:69-76.

110. Ranieri VM, Suter P, Tortorella C, et al. Effect of mechanical ventilation on inflammatory mediators in patients with acute respiratory distress syndrome. JAMA. 1999;281:54-61.
111. Tremblay L, Valenza F, Ribeiro S, Li J, Slutsky AS. Injurious ventilatory strategies increase cytokines and c-fos ,-RNA expression in an isolated rat lung model. J Clin Invest. 1997;99:944-952.

112. Rewa O, Muscedere J. Ventilator-associated pneumonia: update on etiology, prevention, and management. Curr Infect Dis Rep. 2011;13:287-295.

113. Brenner B, Corbridge T, Kazzi A. Intubation and mechanical ventilation of the asthmatic patient in respiratory failure. $J$ Emerg Med. 2009;37:S23-S34.

\section{Publish your work in this journal}

Open Access Emergency Medicine is an international, peer-reviewed, open access journal publishing original research, reports, editorials, reviews and commentaries on all aspects of emergency medicine. The manuscript management system is completely online and includes a very quick and fair peer-review system, which is all easy to use.

\section{Dovepress}

Visit http://www.dovepress.com/testimonials.php to read real quotes from published authors. 